\title{
Percepciones de la fiesta en la España del siglo XVIII: la mirada ajena
}

\author{
Ramón Maruri Villanueva*
}

RESUMEN

La fiesta en la España Moderna, con acusada preferencia la pública y barroca, ha venido siendo, desde 1980

fundamentalmente, un campo historiográfico bien frecuentado por los investigadores.

Enmarcado en él, el presente trabajo se centra en cómo fue percibida por un conjunto de extranjeros que recorrieron la España del siglo XVIII. Sus percepciones, que hemos llamado mirada ajena, nos son conocidas a través de la denominada literatura de viajes y hablan de la fiesta pública y privada, profana y religiosa, civil y politica.

Dicha literatura, que no habia sido utilizada con carácter sistemático en monografias sobre la fiesta, hemos considerado que podia iluminar tanto aspectos de ésta como de la mentalidad de quienes la recrearon en sus diarios y cartas: cuáles

\section{ABSTRACT}

Since about 1980 festivities in Spain of the Ancien Régime, with a marked preference for public and baroque festivities, have been a historiographic field frequently studied by researchers. Set in the frame of reference of this field, this work centers on how festivities were perceived by a group of foreigners who traveled around Spain in the eighteenth century. Their perceptions, which we call the foreign perspective, are known to us through what is called travel literature, and speak about various kinds of festivities: public and private, secular and religious, civilian and political. We believed that this literature, which had not been used systematically in studies of festivities, could shed light not only on facets of the festivities themselves but also on aspects of the mentality of those that described them in their diaries and letters: which

* Departamento de Historia Moderna y Contemporánea. Universidad de Cantabria. 
llamaron su atención; qué juicios les merecieron; en qué medida algunos

de éstos sirvieron para construir, perpetuar o atemperar estereotipos; qué cambios pudieron producirse en los rituales festivos y de qué cambios en la realidad social podian dar cuenta; en qué se desviaba, o no, la percepción de los viajeros de la de españoles de la época o de la imagen recuperada por la investigación histórica contemporánea. festivities captured their attention; what judgments they made about them; to what extent these judgments served to construct, perpetuate or moderate stereotypes; what changes might have taken place in the festive rituals and what changes in the social reality they could reveal; in what respects the perception of the travelers differed from that of Spaniards of the time or from the image recovered by contemporary historic research.

"Mal se conocería el carácter y las costumbres de un pueblo si no lo viéramos más que en sus relaciones serias y bajo el imperio de sus pasiones. Sus fiestas, sus juegos, sus aficiones nos lo dirán mejor».

Barón de Bourgoing

De esas fiestas a que se refiere el barón de Bourgoing en su viaje por España entre 1777 y 1795 es de lo que trataremos en las páginas que ésta abre. $Y$ también de las formas recreativas -digamos de esos juegos y aficiones a los que igualmente alude el noble y diplomático francéspropiciadas por ellas.

Fiestas promovidas por los poderes civil y eclesiástico y por la sociedad, ésta a través de personas privadas sin más. Fiestas que, al margen de su duración, dejaban en suspenso transitoriamente el tiempo ordinario.

Y vamos a tratar de ellas desde la perspectiva de algunos habitadores de allende la otra ladera — de los Pirineos, se entiende-; de ahí lo de la mirada ajena que se anuncia en el título del trabajo.

Mirada de quienes vinieron a España en un siglo, como fue el XVIII, durante el cual se aceleró una práctica que contaba ya con una muy larga tradición: la del viaje. Paul Morand ha escrito que "Desplazarse, ir de un punto a otro, es una característica de las especies superio- 
res"'; en consecuencia, viajar es una actividad inherente al ser humano. Viajar, además, a mil y un lugares, por mil y un motivos y hasta de forma imaginaria; viajes a espacios concretos e, incluso, a ninguna parte; viajes fantásticos al encuentro con lo exótico o con la utopia; viajes a espacios de la escatología; viajes bíblicos e inciáticos, al interior de uno mismo y hasta sentimentales; viajes al pasado y al futuro, al universo infinito y, ya hoy, al laberinto de Internet y a lugares virtuales, realización plena de los anhelos del viajero sedentario. Viajes protagonizados por individuos de todos los grupos que configuran una sociedad.

Mas, viniendo al terreno de las concreciones y de los objetivos que perseguimos, de esa incompleta tipología de itinerarios nos interesan los convencionales. Por supuesto que tan sólo algunos de los que sus protagonistas dejaron testimonio por escrito con el fin de darlos a conocer al público y que, en su conjunto, acabarían configurando un género narrativo -subgénero para algunos- como es el de la literatura de viajes?

Surgida ésta en la Antigüedad, se continuó a lo largo de la Edad Media hasta consolidarse en la Moderna. No obstante, dentro de tan dilatada secuencia temporal, será el siglo XVIII el de la abundancia de libros de viajes, de cartas y de diarios al respecto. Los autores de estos materiales anotaron lo que vieron, lo que les contaron y también, cosa nada infrecuente, lo que imaginaron.

Lo que vieron, les contaron e imaginaron sobre una Europa - por movernos dentro de nuestro entorno continental- recorrida parcialmente: por lo general la encuadrada en lo que los ingleses dieron en denominar el Grand Tour, un itinerario, concebido por y para las elites sociales con fines formativos, en el que se integraban básicamente Francia, Italia, los Paises Bajos y otros ámbitos, sobre todo de la Europa central ${ }^{3}$. La ausencia de España de tal itinerario, fruto de ser valorada como una nación sin interés alguno, no significa, sin embargo, que careciera de visitantes - franceses, ingleses, italianos y alemanes mayoritariamente-como tendremos ocasión de ver ${ }^{4}$.

Citado por Taberina A., "Diez reflexiones sobre el viaje", Revista de Occidente, núm. 193 (1997), pág. 136.

Véase esta voz en Esievanez Calderon, D., Diccionario de términos literarios. Madrid. Ed. Alianza, págs. 1.078-1.080 pág. 51.

Gufrarfo, A. C., Viajeros británicos en la España del siglo xvmi. Madrid, Ed. Aguilar, 1990, 54. 
La literatura de viajes en Europa como fuente para el análisis histórico no es un hallazgo de la historiografía actual, pues cuenta ya, cuando menos, con un siglo de tradición ${ }^{5}$. Tal literatura, a la que en España la Universidad de Murcia dedicó unas jornadas hace ahora tan sólo dos años ${ }^{6}$, ha sido utilizada por los historiadores, nacionales y extranjeros, desde múltiples ópticas, dando lugar a trabajos espacial y temáticamente bien diversificados y de desigual entidad ${ }^{7}$. A ella, por cierto, ha debido buena parte de su vigor la perpetuación de estereotipos estrechamente asociados a la leyenda negra ${ }^{8}$.

Todo lo cual, unido a los problemas del subjetivismo, de la desigual magnitud del territorio visitado y de la también desigual duración de la visita, conduce de modo ineludible a interrogarse por el grado de validez de la literatura de viajes como fuente para el historiador; más aún cuando hubo viajeros, los denominados fireside travellers, que, incluso, no viajaron, que fabularon a partir de lo escrito por otros que sí lo hicieron ${ }^{9}$; o cuando, en otros casos, sobremanera en el del intento - siempre vanode trazar, muy al gusto de la época, unos únicos rasgos psicológicos del español, el viajero generaliza y le asigna los del habitante de una ciudad o región, olvidándose de una característica sustancial de la población española $-y$ de cualquier otra-, como es su diversidad.

Aun con todo, el historiador halla en los libros de viajes, en palabras de Domínguez Ortiz, «muchas cosas aprovechables, ya para el estudio de la realidad objetiva, ya de la mentalidad del observador» ${ }^{10}$. Re-

Véanse en este sentido las actualizadas bibliografías incorporadas a los más recientes trabajos de: Ibidem; FREIXA, C., Los ingleses y el arte de viajar. Una visión de las ciudades españolas del siglo xvim. Barcelona, Eds. del Serbal, 1993; Echevarria Pereda, E., Andalucia y las viajeras francesas en el siglo Xix. Málaga. Universidad de Málaga, 1995.

Cammona Fernandez. F. y Martinez Perez, A. (eds.). Libros de viajes. Actas de las Jornadas sobre Los libros de viaje en el mundo románico. Murcia, Universidad de Murcia, 1996.

Como expresiva muestra de la diversidad de trabajos debidos a la literatura de viajes en España remitimos a la nota $n^{0} 5$ del nuestro. El planteamiento general por lo que al siglo xVII se refiere debe complementarse con la consulta de los trabajos que M. Batllori Munné y L.M. Enciso Recio dedican a los viajes de extranjeros por España en la Historia de España de Menéndez Pidal. Madrid, Ed. Espasa-Calpe, 1987, Tomo XXXI-1, págs. XI-XXV y 5-12, respectivamente; referido más a los viajeros españoles dentro y fuera de España en el setecientos, véase igualmente el artículo de FabBri, M. "Literatura de viajes", en Aglil ar Pinal., F. (Ed.). Historia literaria de España en el siglo xvm. Madrid, Ed. Trotta-CSIC, 1996, págs. 407-423.

* Garcia Carcel, R., La leyenda negra. Historia y opinión. Madrid, Ed. Alianza, 1992, págs. 121 y ss. en especial 158-162.

Guerrero, A. C., op. cit., pág. 27; una nómina y valoración de tal tipo de viajeros pueden hallarse en los trabajos, ya citados, de M. Batllori y R. García Cárcel.

Dominguez Ofitz, A., Sociedad y Estado en el siglo xvil español. Barcelona, Ed. Ariel, 1976, pág. 122; también, sostenedores del mismo criterio, ENCiso RECIO, L. M., op. cit., pág. 10 y Guerraro, A.C., op. cit., págs. 15-55 passim. 
firiéndose no ya a la realidad social española, sino a la de la Europa Moderna, A. Maczak afirma: "Le resultaría difícil al historiador interesado en los detalles de la vida diaria encontrar una fuente mejor de información" que los apuntes de los viajeros en sus cuadernos ${ }^{11}$. En efecto, en los libros de viajes hay anotaciones, a veces muy breves, capaces de iluminar aspectos de la cotidianidad que no siempre otros testimonios nos permitirían hacerlo.

Pues bien, tales libros han sido nuestras fuentes. Libros que reflejan las impresiones de una veintena de viajeros que en distintos momentos del siglo XVIII recorrieron buena parte de los caminos españoles; viajeros por distintos motivos, representantes, sobre todo, de sectores socio-profesionales relevantes - nobleza, burocracia, milicia, Iglesia, letras-y de nacionalidades fundamentalmente francesa e inglesa ${ }^{12}$. Entre ellos se encuentran algunos de los más reputados por su fiabilidad entre los historiadores, dado el acreditado rigor de sus descripciones, caso, por ejemplo, de Beaumarchais, del citado Bourgoing, de Dalrymple, SaintSimon, Swinburne o Townsend. La razón de haberles otorgado el protagonismo informativo es que, coincidente nuestro punto de vista con el de Domínguez Ortiz, la mirada del otro, mirada ajena, puede iluminar tanto aspectos de lo mirado como del universo mental de quien mira.

Lo mirado en este caso es, recuérdese, la fiesta, un campo cuyo análisis en España, centrado con carácter casi exclusivo en la fiesta pública, ha merecido generosa atención por parte de investigadores, nacionales y extranjeros, pertenecientes a disciplinas diversas: Historia Social y Política, de la Cultura, del Arte, de la Literatura -en la vertiente dramatúrgica, en especial-, Antropologia y Sociología.

Desde 1980, punto de arranque efectivo y sistemático de la historiografía española relativa a la fiesta, los trabajos publicados hasta hoy superan los dos centenares, lo cual habla, en principio ya, de esa generosa atención de los investigadores a la que acabamos de referirnos y, también, de la multidisciplinariedad y multiperspectivismo desde los que ha sido contemplada.

Maczak. A., Viajes y viajeros en la Europa Moderna. Barcelona, Ed. Omega, 1996, pág. 47. La práctica totalidad de los libros de viajes que hemos analizado se recogen en Garcia MthCadal, J. Viajes de extranjeros por España y Portugal. III. Siglo xvilt. Madrid. Ed. Aguilar. 1962. Hemos trabajado también con: JARoine, A., Letters from Barbary, France. Spain. Portugal. etc. By an English Officer. London. Ed. T. Cadell, 1788, Vol. II, págs. 1-400: Swineurne., H., Travels through Spain, in the years 1775 and 1776. In which several monuments of Roman and Moorish architecture are illustrated by accurate drawings taken oh the spot. London, Ed. P. Elmsly, 1779. 
Por lo que respecta a la Edad Moderna, en esos trabajos se analiza desde la fiesta renacentista hasta la barroca, ésta, sin duda alguna, la más atendida; desde la motivada por el nacimiento o proclamación de un rey o de un miembro de la familia real hasta la que da lugar la celebración de sus exequias; desde las reflexiones conceptuales, metodológicas y eurísticas hasta los análisis empíricos de carácter general o sectorial, tanto temática como espacial como cronológicamente; desde la fiesta como publicística del poder hasta la fiesta como forma de sociablidad o catalizadora de tensiones y revueltas sociales; desde la disección formal de la fiesta hasta su análisis como universo simbólico y ritualizado. Agréguense a tan sumario e incompleto apunte los trabajos que abordan distintos problemas conexos con lo festivo, léase la religiosidad, la pirotecnia, la emblemática, el uso estético del espacio, etc. ${ }^{13}$

En nuestro análisis habremos de movernos por territorios de festividad y recreo que abarcan lo individual y lo social, lo privado y lo público, lo profano y lo religioso, lo civil y lo político; territorios de fronteras difusas que dan cabida, por ejemplo, al festejo taurino y a la representación escénica, al refresco y a la procesión, al baile y a la exhibición ecuestre.

Pero antes que fiestas, lo que el ojo del visitante extranjero percibió - - o le interesó percibir - fue un español definido por la, llámese, indolencia, holgazanería o pereza. La no laboriosidad, uno de los componentes del estereotipo negativo del español, definía tanto a los nobles — satisfechos con la mera percepción de rentas- como a los comerciantes - de cuya pasividad obtenian provecho sus colegas extranjeros residentes en España-, como al campesino y al artesano, uno y otro beneficiarios de un calendario laboral notablemente menguado. De éste afirmaba el mé-

Una actualizada guia bibliográfica y una precisa panorámica historiográfica relativa a la fiesta pública en España y en otras naciones en la Época Moderna la proporciona LopEz, R. J., Ceremonia y poder a finales del Antiguo Régimen. Galicia 1700-1833. Santiago de Compostela, Universidad de Santiago de Compostela, 1995; puede consultarse también MONTEAGUOO ROBLEDO, $\mathrm{M}^{\geqq}$. P.. "Fiesta y poder. Aportaciones historiográficas al estudio de las ceremonias políticas en su desarrollo histórico", Pedralbes, núm. 15(1995), págs. 173-204. Independientemente de artículos aparecidos en diversas publicaciones y revistas, la última aportación de carácter monográfico de la que tenemos noticia es el trabajo, coordinado por ROMERO FERRER, A., Juego. Fiesta y Transgresión, 1750-1850. Cádiz, Universidad de Cádiz, 1995. A modo de ejemplo tan sólo de esos trabajos a los que hemos aludido sobre problemas relacionados estrechamente con la fiesta pueden verse: Diez Boroue, J. Ma . (comp.). Teatro y fiesta en el Barroco. España e Iberoamérica. s.l., Eds. del Serbal, 1986; FERnANDEZ ARENAS, J. (coord.), Arte efimero y espacio estético. Barcelona, 1988; de más reciente publicación, desde la perspectiva antropológica, PIT?-RIVERS, J. y Pt.RISTIANY, J. G. (eds.), Honor y gracia. Madrid, Ed. Alianza, 1993; a lo largo de nuestro trabajo pueden hallarse algunas otras referencias bibliográficas de interés en este sentido. 
dico y eclesiástico inglés J. Townsend durante su estancia española de 1786-1787: "Las fiestas multiplicadas tienden a despoblar un pais [...], de manera que si se llevan en cuenta las horas de ociosidad, se verá que no queda más de un tercio, y tal vez incluso más de un cuarto para el trabajo» ${ }^{14}$.

No es éste sin más un tópico reiterado en exclusiva por los foráneos, pues en la España del siglo XVIII son habituales los testimonios, debidos ante todo a nuestros ilustrados, que, al asimilar riqueza a productivismo - concepto este último radicalmente enfrentado al de fiesta y también radicalmente ajeno a las sociedades tradicionales-, reforzarían las palabras del inglés ${ }^{15}$.

Pero es que, además, la parvedad del calendario laboral español, y en consecuencia la holganza a que daba lugar, tampoco era privativa de España. E.P. Thompson, uno de los pioneros, sabido es, en el análisis del tiempo laboral y del proceso de normalización de la disciplina de la mano de obra en la Europa de finales del Antiguo Régimen, afirma al respecto:

"Podemos [...] constatar que la irregularidad de dias y semanas de trabajo se insertaba, hasta las primeras décadas del siglo xix, dentro de la más amplia irregularidad del año de trabajo, salpicado por sus tradicionales fiestas y ferias" 16 .

Irregularidad acentuada, según el mismo autor, por la práctica institucionalización del denominado "San Lunes", que el cuerpo demandaba para recuperarse de los excesos del alcohol durante el fin de semana: "San Lunes era venerado casi universalmente dondequiera que existieran industrias de pequeña escala, domésticas y a domicilio» ${ }^{17}$. De tal veneración en el caso de España da cuenta el citado Townsend, quien, refi-

Garcia Mehcadal., J., op. cit., pág. 1.510.

En la Cantabria de 1798 uno de esos ilustrados - por referirnos tan sólo a un ejemplo "en provincias"- denunciaba que, de los trescientos sesenta y cinco dias del año, "apenas quedan ciento cuarenta útiles». M[ANSO]. J., Estado de las Fábricas. Comercio, Industria y Agricultura en las montañas de Santander (s. xVIII). Santander, Ed. Libreria Estudio, 1979, pág. 202 (Edición de Tomás Martínez Vara).

ThOmpson, E. P. Costumbres en común. Barcelona, Ed. Crítica, 1995, pág. 423. Para un desarrollo más amplio de los problemas del tiempo como factor organizador de relaciones sociales y como concepto a través de la historia remitimos eminentemente a: EliAS. N. Sobre el tiempo. Madrid, Ed. Fondo de Cultura Económica, 1989; Ramos TorRe, R. (comp.), Tiempo y sociedad. Madrid. CIS-Siglo xxI, 1992; Willtrow. W., El tiempo en la historia. La evolución de nuestro sentido del tiempo y de la perspectiva temporal. Barcelona, Ed. Crítica, 1990.

THOMPSON, E. P., op. cit., pág. 420; ampliación sobre "San Lunes" en págs. 418-424. 
riéndose al territorio arzobispal de Toledo, manifiesta que en él los aprendices y los jornaleros reclamaban los lunes "para sus recreos" ${ }^{18}$.

Matizado, pues, el estereotipo del carácter indolente del español, al observarse que en cuestiones de tiempo improductivo nuestros compatriotas respondian en lo esencial a pautas europeas, quedaría por abordar qué contenido festivo, se entiende que desde la óptica del "otro", tenía ese tiempo.

Pero antes otra matización: que dicha óptica tiene una buena dosis de parcialidad, pues es la de unos viajeros que se mueven con acusada preferencia en marcos urbanos, y, además, no en los de la totalidad del territorio español; que frecuentan más los salones de las elites sociales que las tabernas; que están más atentos a describir cómo salen de palacio los miembros de la familia real que cómo festeja un bautizo un artesano o un campesino; etc.. Que escriben, en definitiva, para un público que no pertenece precisamente al campesinado o a los sectores populares urbanos.

Para esos viajeros hablar de fiesta es hacerlo, ante todo, de la de los toros, debilidad y pasión, según ellos, de los españoles: "los hombres, las mujeres y los niños, el rico y el pobre, todos la prefieren a cualquier otro espectáculo público" ${ }^{19}$. Y aunque el italiano $G$. Casanova escribiera en 1768 que "es preciso ser español para saborear su encanto» ${ }^{20}$, en quienes visitaron España ejerció una singular atracción, si tenemos en cuenta que, en el conjunto de comentarios que dedicaron a festejos, los relativos a la tauromaquia son, sin duda alguna, los más extensos y enjundiosos.

La "fiesta de los toros", así nombrada con frecuencia, lo era por sí misma, al constituir un histórico componente, aunque no exclusivo, del ciclo festivo del verano ${ }^{21}$. Y lo era también por ser susceptible de formar parte de otras fiestas, desde las del rey hasta las de la Iglesia.

Los adjetivos que le dedican abarcan un amplio registro en el que coexisten, paradójicamente, los relacionados con la crueldad y la audacia, la barbarie y la grandeza, el estremecimiento y el preciosismo, pues la fiesta taurina provocaba en los extranjeros, en cada uno de ellos, no un sentimiento univoco, sino dual. En apoyo de esta valoración acudimos, más que a la exhaustividad de la casuística, a su expresividad, como la que im-

Garcia Mercadal. J., op. cit., pág. 1.510

TOWNSEND, Ibidem, pág. 1.431

ibidem, pág. 624

Caro Baroja, J., El estio festivo (Fiestas populares del verano). Madrid, Ed. Taurus, 1984 págs. $241-274$ 
pregna las palabras del inglés mayor W. Dalrymple -1774-: “El primer ataque del toro por un hombre a caballo tiene verdaderamente algo de noble y de valiente que agrada, pero el fin, que yo llamaría mejor la carnicería, es un espectáculo muy desagradable» ${ }^{22}$. La carnicería la provoca no el cuerpo a cuerpo del torero y el toro, sino, fundamentalmente, la feroz lucha del toro contra otros animales: contra los perros que, en determinadas circunstancias, solían soltarse en la plaza para que lo debilitaran, pero, sobre todo, contra los caballos del rejoneador o del picador, de tal modo que son varios lo viajeros que - ia modo de tópico? - refieren haber visto morir cinco o seis caballos "despanzurrados» en la propia plaza; Townsend va mucho más allá al hablar de trece, "Incluso ha ocurrido alguna vez el que [los toros] matasen sesenta caballos en un dia» ${ }^{23}$.

Porque, reiterando la idea anterior, era el enfrentamiento del toro con el torero lo que se consideraba dotaba de grandeza al espectáculo. Esto escribia en 1765 el conde sueco G.F. Creutz:

"Es imposible asistir a ellas [a las corridas] sin sentir el alma elevada; nada iguala la ferocidad de esos animales, a no ser el valor y la ligereza de los toreros. Nobles actitudes, altivas y bien dibujadas realzan su superioridad; su destreza sobrepasa todo lo que pueda imaginarse. En eso [en vencer al toro] es en lo que se ve la superioridad del hombre y lo que puede la inteligencia contra la fuerza ciega» ${ }^{24}$.

Probablemente E. Gil Calvo, en su espléndido ensayo de socio-antropología histórica sobre las funciones de las corridas de toros, no hubiera desdeñado servirse de ese testimonio para ilustrar lo medular de su tesis:

"Dado que las corridas representan la lucha victoriosa de la razón humana enfrentada a fuerzas incontroladas mucho más poderosas, su institucionalización se inscribe dentro del vasto proceso de modernización económica, sociopolítica y cultural que por aquellas fechas recorría toda Europa, con motivo de la disolución de la sociedad estamental» 25.

Mas no sería sólo el noble sueco quien mereciera ser citado por Gil Calvo. La virtualidad y el interés de lo testimoniado por los viajeros relativo a los toros no radicaría solamente en aportarnos información más o

Garcia Mtracadal, J., op. cit., pág. 667.

lbidem, págs. 1.429-1.430.

lbidem. pág. 586. Puede consultarse también, por su intensidad narrativa. un fragmento similar del texto de Bourgoing en pág. 1.009.

Gl! CaLvo, E.. Función de toros. Una interpretación funcionalista de las corridas. Madrid. Ed. Espasa-Calpe, 1980, págs. 26-27 
menos detallada de una forma compleja de recreo, de cómo ha sido valorada o de qué papel le correspondió en la construcción de la imagen de la España romántica. Tales interés y virtualidad tienen más vigor, creemos, por la capacidad de los testimonios de evidenciar ese proceso de cambio enmarcado de lleno en el siglo XVIII al que se refiere Gil Calvo. Un proceso que éste articula conceptualmente y que consiste, en sintesis, en el tránsito de una fiesta taurina "feudal-casticista", en la que los dos poderes contendientes - el caballero y el toro- "exhiben una potencia de ataque que, si bien puede ser ligeramente desigual [...], representa, en todo caso, un orden equivalente de magnitud" "26, a una fiesta "urbano-burguesa", definida por el triunfo del torero, de "la destreza, la profesionalización y la tecnificación» 27.

De tal proceso, pues, fueron atentos testigos, aunque carentes de las claves para su interpretación, quienes visitaron España en el setecientos. Ellos nos hablan, en algunos casos parece que lamentando que así ocurriera, de una fiesta que de privativa en otro tiempo de caballeros se ha aplebeyado. En 1755, tres décadas y media antes de que Jovellanos redactara su Memoria sobre los espectáculos públicos, en los que da cuenta del fenómeno, el sacerdote italiano N. Caino había escrito:

"Hubo un tiempo en que los señores y los grandes del reino entraban en la liza, y el espectáculo era entonces mucho más brillante que ahora [...]. Ahora no son más que gentes pagadas para eso las que allí aparecen, y la magnificencia es mucho menor, porque nadie está ya interesado en darle brillo» 28 .

En efecto, la descripción que de las corridas de toros se hace desde 1750 aproximadamente - aunque el proceso al que aludiremos emerge en alguna década anterior- muy poco tiene que ver ya con la de un anónimo viajero que había visitado la España del último cuarto del siglo xvII. En el relato de éste, fiel pintura del ritual taurino barroco o "feudal-casticista", los antagonistas del toro eran esos "señores y grandes del reino" de que hablaba el padre Caino, siendo asistidos por "gran número de cria-

Ibidem. pág. 37.

Ibidem, pág. 46. Un análisis empírico desde el punto de vista histórico sobre algunos aspectos del cambio, en Cruy Cabrena, J.P., "Las fiestas de toros en la Baeza del siglo xvilt: Entre las pervivencias barrocas y el tránsito al toreo moderno", en Romero FERRER, A. (coord.), op. cit., págs. 219-227.

$\because$ Gafcia Mracaddal, J., op. cit., pág. 411. El texto de Jovellanos al que nos hemos referido, y del que existen diversas ediciones, es Memoria para el arreglo de la policia de los espectáculos y diversiones públicas, y sobre su origen en España. 
dos diversamente vestidos» ${ }^{29}$. Por el contrario, los antagonistas del toro en la corrida "urbano-burguesa» son de otra condición social, y sus razones para ponerse delante de un toro son bien distintas de la mera recreación y exhibición del valor y del espíritu guerrero, caballeresco y galante que definía históricamente a la nobleza. En este otro tipo de fiesta taurina nobles titulados, o hidalgos sin más, no tienen ya cabida en el ruedo.

$Y$ no la tienen, entre otras razones, porque dicha fiesta nunca fue del "real agrado" de los monarcas de la casa de Borbón, al contrario de lo ocurrido con los de la casa de Austria. Ya Felipe V, al poco tiempo de acceder al trono español, comenzó a desacreditar en lo posible las corridas de toros, e hizo algunos intentos de reemplazarlas «por una diversión real a la francesa" ${ }^{30}$. La actitud antitaurina de los Borbones, no exenta de contradicciones, culminará en 1785, cuando una Pragmática de Carlos III prohiba "las fiestas de toros de muerte en los pueblos del reino" ${ }^{31}$-no obstante, la Pragmática es expresión, además de una actitud personal del monarca hacia los toros, de los temores del poder político a que los tumultos inherentes a los espectáculos taurinos desembocaran en la confrontación social violenta; a los mismos temores que respondía la proscripción de los contenidos más genuinos del Carnaval, de ahí que sea ésta una fiesta apenas mencionada por los viajeros ${ }^{32}$.

Así, pues, lo que al rey no agradaba mejor desestimarlo; luego, lo pertinente era, por lo que a los caballeros se refiere, al menos replegarse desde el ruedo a los palcos y balcones; y replegarse también, sobre lo que volveremos más adelante, hacia juegos ecuestres de aroma medievalizante. Sin embargo, dado el arraigo de la fiesta taurina en la cultura española, tal repliegue no crearía un vacío, pues los caballeros serían sustituidos por "picadores", "banderilleros" o "chulos" y "matadores» 0 "toreadores".

De este modo dicha fiesta fue profesionalizándose: "Cada acto de esta tragedia está marcado por las músicas", escribe el diplomático francés

Descripción del viajero anónimo, en Garcia Mericadal, J.. op. cit., págs. 74-79.

Borrineau. Y., El arte cortesano en la España de Felipe V (1700-1746). Madrid, F.U.E. 1986. pág. 328.

Citado, Cossio, J.Ma de Los toros. Madrid, Ed. Espasa-Calpe, 1995, Tomo I, pág 122

$\mathrm{RiO}, \mathrm{M}$. J. del, "Represión y control de fiestas y diversiones en el Madrid de Carlos $\mid \mathrm{H}$ », en EQUipo MADRID, Carlos III. Madrid y la llustración. Contradicciones de un proyecto reformista. Madrid, Ed. Siglo $\times x 1,1988$, págs. 327-328, 321-323, respectivamente, y passim. Swinburne relata que en el populoso y bullicioso Cádiz de 1775 el único indicio de vivirse el carnaval, por hallarse prohibidos los bailes y las mascaradas públicas, era que las mujeres, desde los balcones de sus casas, arrojaban calderos de agua a los hombres que pasaban por la calle, SWINBURNE, H., op. cit., pág. 228. 
J.P. Peyron en la década de $1770^{33}$. Actos o suertes -orden de la lidiadispuestos por el presidente de la corrida, anunciados con clarines y ejecutados, tras haberse producido una, digamos, división del trabajo taurino, por esos picadores, banderilleros y matadores a que antes aludiamos.

Estos profesionales no son ya sujetos anónimos, actores de un espectáculo coral, como ocurre, por ejemplo, en los encierros, corridas de vaquillas, toros ensogados, toros embolados $u$ otras modalidades de festejos taurinos, muy enraizadas en el mundo rural y tan espléndidamente analizadas por M. Delgado ${ }^{34}$. En tales modalidades, en donde el individuo se despersonaliza al disolverse en el grupo, es impensable la autoría, como también lo es en el acoso y muerte de esos toros que, en las plazas urbanas, según testimonian los propios viajeros, suelen entregarse al "populacho» o "canalla» para su diversión.

En el siglo XVIII surgen nombres propios que pasarán a formar parte de la leyenda y de las raíces modernas del toreo. Nombres como los de "Costillares", "Pepehillo» y "Romero", de quienes nos informan, a partir ya de la década de los setenta, Bourgoing. Townsend y Peyron; este último escribe: "Se ha visto a la nación dividida entre los dos más famosos toreadores que existen: Romero y Costillares. Los nombres de romeristas y costillaristas que se dan los dos partidos prueban el encarnizamiento con que defendían cada uno su opinión» 35; y Bourgoing da noticia de que "el famoso torero Pepe Hillo acaba de publicar un tratado titulado La tauromaquia $O$ arte de torear,...” ${ }^{36}$, ejemplo de tecnificación y codificación de la fiesta.

Acogiéndonos a la hipótesis interpretativa de Gil Calvo sobre las corridas de toros, éstas, indisociables de la aparición del torero individuado, fugitivo del anonimato - metáfora del sujeto moderno, adulto y responsable-, y con destreza - del diestro-, constituyen un fenómeno de ilustración y modernización, "puesto que celebran el triunfo de la libre elección racional sobre el muy superior poder de las fuerzas de la brutalidad, el estamento, la casta, el prejuicio, la superstición y el atavismo" ${ }^{37}$. Recordemos en este sentido las palabras de Creutz exaltando el triunfo de

Garcia Mehcadal, J., op. cit., pág. 806.

Delgado Ruiz, M. De la muerte de un Dios. La fiesta de los toros en el universo simbólico de la cultura popular. Barcelona, Ed. Peninsula, 1986. Una visión global de las diversas modalidades de testejos taurinos, en Cossio, J. $M^{a}$. de, op. cit., Tomo I, págs. 681-705.

Garcia Mercadal. J.. op. cit., pág. 806.

Ibidem, pág. 1.010. Sobre el papel jugado en la historia de la lidia por los tres toreros citados véase Cossio, J. M $\mathrm{M}^{\sharp}$. de, op. cit., Tomos $\mid$ y II, passim.

Gı CAI.vO, E., op. cit., pág. 160. 
la inteligencia sobre la fuerza, de la razón sobre la naturaleza, es decir, del torero sobre el toro.

Lo que Gil Calvo propone es, siguiendo en esto a Delgado Ruiz, que la fiesta de toros sea contemplada como «una pedagogía, una didáctica y una lección moral" al servicio de la llustración. Pero no la oficial, que a través de gestos políticos y medidas legislativas buscó dificultar, hasta prohibir, dicha fiesta. No esa llustración, elitista y descendente, sino otra que se constituye desde abajo, desde la propia base social; sólo que los signos de transmisión del discurso ilustrado - o al menos de una parte de él- no se hallaban en los textos filosóficos al uso, sino en el código estético de la tauromaquia. El sociólogo para nada sostiene que la corrida de toros simbolice la disolución del Antiguo Régimen, pero sí que constituye un momento en el tránsito del modelo de sociedad del barroco al de sociedad ilustrada ${ }^{38}$.

La plaza de toros representaría, así, el «templo español donde se celebra la ceremonia de la modernidad", aunque bajo el "deformante y esperpéntico" manto de la corrida ${ }^{39}$. La plaza de toros sería imagen del cambio social que comenzaba a operarse en la España del setecientos, consistente en buena medida en que un minoritario sector del tercer estado - la burguesía - vendría a ocupar su propio espacio en el "ruedo" social junto a la nobleza; aunque, eso sí, una nobleza que no respondía ya toda ella a la del modelo barroco. La plaza de toros sería, en fin,

\footnotetext{
"el lugar de la visibilidad y transparencia social, donde todas las clases sociales pueden sentarse frente a frente para sopesar sus diferencias, momentáneamente igualados por la extasiada contemplación del espectáculo que se representa" ${ }^{40}$.
}

Existe también otro significado en la polisémica corrida de toros que no se le escapó a algún viajero: el económico. Son varios los que establecen un nexo entre corrida de toros y negocio de la carne. Una breve cita de Jardine -1788 - al respecto: "Los caballeros pocas veces participan últimamente en el toreo, sino que se deja a gladiadores contratados, generalmente carniceros de profesión" ${ }^{41}$. Carniceros -qué realidad tan distinta de la de los caballeros oficiantes de las corridas en otro tiempoque, a la vez que profesionalizaban y tecnificaban de forma progresiva la fiesta, trabajaban ritualmente al toro para, en palabras nuevamente de Gil

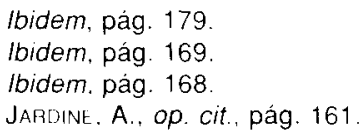


Calvo, "transformar la materia prima de su fuerza bruta en un producto elaborado, refinado y acabado [...] extrayéndole todo su beneficio" a través de su venta pública para el consumo ${ }^{42}$.

Probablemente, ya en el setecientos, la sola satisfacción del goce estético -o morboso- producido por una corrida de toros no justificara sin más ésta. Una cuantificación diacrónica del número de corridas y del de toros lidiados en cada una de ellas tal vez iluminase aspectos hasta ahora insuficientemente conocidos sobre la evolución del consumo de carne de vacuno y su incidencia en el sacrificio “industrial» de reses. Desde luego, la lidia por la lidia a que nos referíamos líneas arriba difícilmente pudiera justificar, creemos, el dato aportado por el minucioso Townsend relativo a que en Madrid, en 1786 - a pesar de la reciente prohibición de 1785-, se celebraban corridas de toros «cada semana y a menudo dos veces por semana durante el verano; y cada día seis víctimas mueren por la mañana y doce por la tarde» ${ }^{43}$; refiriéndose a Sevilla, Peyron manifestaba en 1772 que "Hay $[. .$.$] regularmente de dos días uno, durante una semana, veinte$ toros de muerte» ${ }^{44}$. $\mathrm{Si}$, según ambos testimonios, se llegaba a dar muerte en una y otra ciudad a tan considerable cantidad de astados algunas semanas, no hay duda de que algún tipo de presión tendría que ejercer la propia demanda de carne de toro. Aunque hay que tener en cuenta que los casos de Madrid y de Sevilla no eran la norma, al tratarse de dos de los más grandes núcleos urbanos de la España de finales del siglo XVIII.

Por otro lado, habría que considerar, lo cual desconocemos, si la capacidad económica de los potenciales espectadores les permitía acudir sistemáticamente a las corridas, teniendo en cuenta que el acceso a la plaza de toros no era gratuito. Ateniéndonos al testimonio de Bourgoing, en el Madrid de 1780-1790 «Las localidades más baratas cuestan 2 o 4 reales, según sean de sol o de sombra. Las más caras llegan a valer veinticuatro reales" ${ }^{45}$. $Y$ aun teniendo en cuenta la gran capacidad de convocatoria que tenian las corridas en las propias ciudades y los lugares del entorno, y del mismo modo tomando en consideración los frecuentes comentarios de los viajeros relativos a que los españoles prescindirian de

\footnotetext{
42 Gil Calvo, E., op. cit., pág. 49; en páginas 16-25 se desarrolla este problema de las relaciones entre corridas de toros, consumo de proteínas, mataderos y carniceros. Es significativo que a "Costillares» se le concediera la tabla para el despacho de carnes en Madrid, y que Pedro Romero fuera nombrado visitador de las casquerias de Sanlúcar de Barrameda: Cossio, J. Ma . de, op. cit., Tomo II. págs. 692 y 714, respectivamente.

43 Garcia Mercadal, J., op. cit., pág. 1.430.

${ }_{44}$ Ibidem, pág. 806.

45 Ibidem, pág. 1.007.
} 
los más necesario para abonar una localidad en la plaza -esto, sin duda alguna, pertenecería más al capítulo de los estereotipos, todavía hoy en activo-, creemos que los sectores populares urbanos no podrían soportar una asistencia medianamente regular a la plaza; aunque, cierto es, las corridas de toros eran un espectáculo participado por toda la sociedad. Sin embargo, difícilmente se cubrirían de forma sistemática aforos, caso de Madrid, Sevilla o Cádiz, de entre 6.000 y más de 10.000 localidades, según algunos viajeros.

De lo que a éstos no les cabe duda alguna es de que la fiesta taurina da lugar a numerosos gastos que iban, en una cadena de externalidades, desde la propia cría del toro en el campo a su transporte hasta la plaza, al pago de salarios a todo tipo de profesionales que se movian en torno a ella, a la venta de entradas, a la fabricación de objetos ornamentales y ropas específicas para las corridas, al consumo de "vasos de agua hela$\mathrm{da}$, chocolate, dulces de todas clases y colores" ${ }^{46}$, etc.. Bourgoing afirma que los festejos taurinos "ocasionan mucho gasto $[y]$ rinden a los empresarios enormes ganancias» ${ }^{47}$. Townsend, que dice disponer de información "de la mejor autoridad", nos aproxima a la posible magnitud de esas ganancias. En junio de 1786 la recaudación media de la plaza de toros de Madrid «puede ser con exceso calculada en 700 libras [...], lo que deja un beneficio de cerca de 400" ${ }^{48}$; traducidas a reales de vellón, una y otra cifra representarían 70.000 y 40.000 respectivamente ${ }^{49}$.

¿Constituiría esto un atinado ejemplo, siguiendo a J. H. Plumb, de «comercialización del ocio en el temprano desarrollo de una industria del tiempo libre", basada en todo tipo de diversiones "que implicaban un gasto de dinero por parte de los consumidores"? ${ }^{50}$. Probablemente así fuera, aunque esto exige alguna precisión.

En primer lugar, que el recurso a las corridas de toros como medio de obtener ingresos era una práctica que contaba ya con una larga tradición. Las instituciones receptoras de esos beneficios solían ser los municipios y la Iglesia. Townsend y Bourgoing nos dicen cuál era la beneficiaria en el caso de Madrid: el Hospital General de la villa ${ }^{51}$.

\footnotetext{
4. TOWNSEND, ibidem, pág. 943.

lbidem, pág. 1.007.

Ibidem, pág. 1.431

4a La equivalencia de las monedas la hemos hecho a partir de los datos del propio Townsend, lbidem, pág. 1.399.

50 Citado, Rule, J., Clase obrera e industrialización. Historia social de la revolución industrial británica, 1750-1850. Barcelona, Ed. Crítica, 1990, pág. 302.

51 Garcia MERCAdalL, J., op. cit., págs. 1.430 y 1.007 , respectivamente.
} 
En segundo lugar, este mecanismo de explotación de las corridas de toros no representaba ninguna excepcionalidad, ya que también se aplicaba a los teatros, caso, por ejemplo, del de Valladolid, cuyos ingresos netos durante el setecientos se repartían, según C. Almuiña, "entre las arcas municipales y el Hospital de los Niños Expósitos, verdadero propietario del edificio del Teatro de la Comedia» 52.

En tercer lugar, lo recaudado por el espectáculo taurino, una vez deducidos costos, se destinaba a atender gastos sociales. De ahí que, en situaciones de emergencia, los poderes político y eclesiástico locales promovieran corridas de toros como medio de recaudar fondos. C. Sanz, refiriéndose a las representaciones teatrales en el Siglo de Oro, habla de que lo obtenido por la venta de entradas se destinaba a "mantener una relativa paz social y dar una solución de subsistencia al creciente número de marginados que se establecieron en aquellos lugares [las ciudades]" ${ }^{53}$.

No menor que la atención de los gobernantes del siglo xvı a la paz social y a los marginados fue la de los del setecientos, que ven avanzar inexorablemente el pauperismo y la marginalidad urbanos como consecuencia del crecimiento demográfico y de las carencias y deficiencias estructurales de la economía. Y aun teniendo en cuenta declaraciones programáticas - y ciertas realizaciones, aunque fallidas- de los políticos ilustrados en materia de beneficencia, el socorro de los pobres continuó siendo asunto eminentemente de la Iglesia. De ahí que, aun a pesar de la prohibición de 1785, Carlos IV, como manifiesta Bourgoing, concediera "con mayor facilidad el permiso para celebrarlas [las corridas] en las ciudades que lo solicitan para dedicar su producto a obras de caridad" ${ }^{54}$.

Sin embargo, en la explotación del espectáculo taurino se movían otras personas, además de los profesionales y de las instituciones ya citados. La corrida de toros exigía de ganaderos, de transportistas, de toreros, etc.; pero también de arrendatarios, pues los promotores del festejo ponían en manos del mejor postor todo lo concerniente a su organización ${ }^{55}$. Sin duda alguna, y a medida que en determinadas localidades las corridas fueron dejando de ser un acontecimiento esporádico para convertirse en un espectáculo habitual -digamos que a partir del tránsito del siglo XVIII al XIX—, en la figura del

Almuina FFrnander. C.. Teatro y cultura en el Valladolid de la llustración. Los medios de difusión en la segunda mitad del xvili. Valladolid, Ayuntamiento de Valladolid, 1974. pág. 103.

5.3 SANz AYAN, C., "El teatro como negocio", Torre de los Lujanes, núm. 27 (1994), pág. 235.

5. Garcia Meircadal, J., op. cit., págs. 1.010-1.011.

it Puede verse un ejemplo de esto en Calin Aparicio, C. y Martine z Mari int 2 , M., "Las fiestas de toros en Cartagena a fines del siglo XVIH: entre el arraigo popular y el control oficial», en Romero Ferrer, A. (coord.), op. cit., págs. 205-217 
arrendatario hay que ver la del protoempresario taurino, explotador ya de la “industria del tiempo libre» y surgido a la sombra del poder político y de la Iglesia.

Institución esta última, por cierto, gran promotora de la fiesta en la España Moderna. En la del siglo XVIII lo percibieron los viajeros y así lo expresaron con palabras más o menos concluyentes. El militar francés $E$. $F$. Lantier - C.1800 - en frase tal vez un tanto desmesurada, dice que «E! soberano bien [para los españoles] es el dormir durante el calor, respirar el fresco al ponerse el sol, tomar chocolate, hacer el amor y asistir a las procesiones y a las ceremonias de la iglesia" ${ }^{56}$.

Dentro de éstas, no son precisamente las específicas del Santo Oficio -en contra de lo que en principio pudiera suponerse, dado lo que la institución connotaba fuera de España- las que merezcan más la atención de los viajeros, pues dicho tribunal, aun siendo calificado de "funesto", "execrable» o “inspirador de terror», es percibido ya como una institución agonizante. De la dramatización por antonomasia del discurso inquisitorial, los autos de fe, se escribe muy poco, y lo escrito se centra en los seguidos contra Macanaz y Olavide. El galo marqués de Langle considera que en 1784 eran "bastante raros" - hacía cuatro años que había concluido el de Olavide, y siete décadas el de Macanaz- y si se celebraba alguno, se hacía, entre otras razones, "para alegrar al pueblo" 5 .

Lo sustantivo de la mirada de los viajeros hacia las manifestaciones festivas del catolicismo español se halla eminentemente en sus testimonios sobre los rituales a que dan lugar las festividades de Semana Santa y del Corpus, sobre todo la primera.

La de la Pasión de Jesús, bien fuera en Madrid, en Segovia, en Málaga, en Granada o en Barcelona, en una u otra década del siglo XVIII, fue valorada con expresiones de esta naturaleza: "Diversión del pueblo", "Fuente de mil sacrilegios", «Perpetuación de la superstición", "Espectáculo horrible de ver», "Tiempo de gran disipación» o "Espantable penitencia". Los bailes en las iglesias, los encapuchados, los disciplinantes y el patetismo tremendista de los sollozos en las procesiones son los que mueven a los viajeros a efectuar tales valoraciones.

También el ritual de la fiesta del Corpus, "Una de las más bellas del año", según Lantier ${ }^{58}$, aunque carente de los componentes lúgubres del

Garcia Mercadal. J., op. cit., pág. 1.266 (el subrayado es nuestro),

Ibidem, pág. 1.333.

Ibidem, pág. 1.272 
de Semana Santa, asombra a los pocos viajeros que dan testimonio del mismo. Lo que los desconcierta son las «locuras y cosas ridículas» protagonizadas por los danzantes, bufones, angelotes y gigantes que participan en los desfiles procesionales. Ya hacia finales del siglo XVII un viajero anónimo habia escrito que algunas de las escenas "pudieran no ser aprobadas en otros paises" ${ }^{59}$.

Además, algún viajero más perspicaz —o más incisivo- de lo habitual no desdeñó establecer conexiones entre devoción y economía. De las procesiones se escribe desde el anonimato en 1765: "Son espectáculos que atraen y ocupan al pueblo, cuyo concurso ocasiona una circulación de dinero que produce un beneficio real a cada ciudad que tiene la dicha de tener una procesión famosa» ${ }^{60}$; y Townsend: «El gran número de procesiones hace el consumo de cera muy considerable en todas las partes de España» ${ }^{61}$.

Todo este derroche devocional y hasta económico, tan enraizado en la cultura popular tradicional, mereció la condena de los viajeros, pero no menos la de los gobernantes españoles y hasta la de los representantes de la jerarquía eclesiástica -ilustrados o no-, que vieron con beneplácito la legislación prohibicionista de Carlos III tendente, además de a evitar la transgresión del orden social, a limitar excesos de acuerdo con las exigencias de la racionalidad y con los postulados del catolicismo ilustrado. Un catolicismo que abominaba también del componente grotesco en las fiestas a que daban lugar peregrinaciones y celebraciones de santos patronos locales o el ritual de difuntos. Como igualmente arremetía contra los autos sacramentales y comedias de santos —prohibidos desde 1765-, «mezcla extraña de sagrado y de profano» en palabras de Caino ${ }^{62}$, con su confusión temática y su cortejo de viajes fantásticos al cielo, al infierno y regreso a la tierra, a espaldas, además, de la preceptiva neoclásica ${ }^{63}$. Apostando por un encuentro de España con la ponderación, Townsend

\footnotetext{
59 lbidem, pág. 73.

60 lbidem. pág. 559.

61 lbidem, pág. 1.445.

6. lbidem, pág. 415.

53 EGIDO, T., "La religiosidad de los ilustrados", en Jover Zamora, J. Ma . (dir.), op. cit., fundamentalmente págs. 410-413; PEREIRA PEREIRA, J., "La religiosidad y la sociabilidad popular como aspectos del conflicto social en el Madrid de la segunda mitad del siglo XVIil", en EQUIPO MADRID, op. cit., págs. 223-254; Palacios Fernandez, E., "Teatro", en Agullaf Piñal, F. (ed.), op. cit., en especial págs. 135-154; Rio, Ma. J. del, op. cit., passim. Sobre la fascinación que en el público ejercia el retablo de maravillas mostrado por esta dramaturgia véase la ya clásica obra de ANDIOC, $R$, Teatro y sociedad en el Madrid del siglo xvim. Valencia, Fundación Juan March-Ed. Castalia, 1976. págs. 345-379.
} 
escribía: "Toda Europa ha salido de ese estado de gótica ignorancia [fuente de superstición], y España, aunque la última, no será, por lo que de ella se puede esperar, la menos ilustrada" ${ }^{64}$.

Continuemos en el ámbito de la fiesta pública y detengámonos en mirar la mirada que los viajeros dirigieron al Estado, instancia, en este caso la monarquía, definidora por antonomasia de lo público.

Las referencias a las fiestas promovidas tanto por los Borbones como por instituciones en honor de ellos son del todo exiguas.

Peyron relata que durante su estancia en Valencia entre 1772 y 1773 acudió a una fiesta en la Plaza Mayor que, con motivo del cumpleaños de Carlos III, organizaba la Real Maestranza de esa ciudad. Fiesta que consisitió en una exhibición ecuestre por parte de los nobles caballeros maestrantes «montados sobre hermosos caballos [...] y seguidos de un numerosos cortejo de criados"; los ejercicios realizados fueron, fundamentalmente, "varias escaramuzas con la espada o la lanza, a imitación de los antiguos torneos", tras lo cual "corrieron la sortija y la cinta".

Se hace patente en el relato de Peyron una complacencia no sólo con el ritual que contempla, sino, sobre todo, con el espíritu que lo alienta:

"Era una imagen interesante e ingenua de aquel tiempo de franqueza y de lealtad, que llamaron el siglo de la caballería. El valor, el amor y el placer estaban en esa fiesta encantadora que se termina por la comida y el baile, en la que cada cabaliero pone la cinta, premio de su destreza, a los pies de su bienamada» ${ }^{65}$.

Poco más de una década después, Townsend asiste a otra fiesta de similares características en la misma ciudad y organizada también por su Real Maestranza. Esta vez el homenajeado era el infante don Antonio Pascual, hijo de Carlos III y gran maestre de dicha institución, "compuesta por la principal nobleza» valenciana. Sus miembros, "montados sobre hermosos y grandes caballos andaluces, marcharon en orden hasta enfrente del retrato [del Rey]; alzaron la cortina, y en el mismo momento todas las espadas fueron agitadas en el aire" ${ }^{66}$. Después se realizaron ejercicios de equitación y juegos "de agilidad y destreza», como el ensar-

4 Garcia Mercadal, J., op. cit., pág. 1.361.

65 Ibidem, págs. 753-754.

${ }^{66}$ Ibidem, pág. 1.640. Sobre el protagonismo de la Real Maestranza valenciana en este tipo de ejercicios ecuestres puede consultarse Minguez, V., «El juego caballeresco. Su resurgimiento en Valencia durante la segunda mitad del siglo XVIII", en Romero Ferrer, A. (coord.), op. cit., págs. $127-135$ 
tar cintas con la punta de la espada desde el caballo lanzado al galope. Por la tarde se continuó con una merienda - un "refresco"- a la que asistieron "seiscientas personas escogidas en las primeras clases de Valencia». Ponia fin a la misma "una pequeña ópera, compuesta para esta ocasión y titulada: La paz entre Marte y el Amor" ${ }^{67}$; asunto -el mitológico- tan caro al teatro neoclásico y especie desusada en una España mayoritariamente devota de la comedia disparatada y de los argumentos inverosimiles.

Hay, además de ésta, otra referencia a una representación escénica integrante de una fiesta asociada a la casa real. La proporciona el noble inglés H. Swinburne, quien, durante su estancia de 1775 en Barcelona, asistió, con motivo de la festividad de San Carlos Borromeo, santo del rey, a la escenificación de El Cid Campeador, "una tragedia histórica de una gran pasión y fuerza de carácter " ${ }^{68}$.

Son ahora de nuevo Swinburne, Townsend y Bourgoing, próximos a los círculos cortesanos, los descriptores de uno de los juegos ecuestres preferidos en las fiestas promovidas por la corte durante sus estancias en el Aranjuez del último cuarto del setecientos: las "parejas",

«débil y fria imagen de los antiguos torneos [que] recordaban un poco a los espectadores, haciéndoselas añorar, aquellas fiestas en que los antiguos caballeros, bajo las miradas de los reyes y las damas, iban impelidos por el doble acicate de la gloria y el amor ${ }^{69}$.

También Burgoing da cuenta de otra forma de recreo patricio, como son las denominadas "fiestas reales", corridas de toros que se celebraban en la Plaza Mayor de Madrid con la asistencia de los monarcas o de miembros de la casa real y que implicaban un ceremonial muy específico, dado su rango ${ }^{70}$. Durante el reinado de Carlos III, que detestaba los espectáculos taurinos cruentos, "sólo hubo una de esas fiestas reales [...]. Pero la coronación del nuevo rey ha dado motivos para ponerlas en boga" ${ }^{71}$.

Rituales todos ellos cortesanos al más genuino estilo de la fiesta barroca, entendiendo ésta, en uno de sus diversos significados, como exal-

Garcia Mercadal., J., op. cit., pág. 1.641.

SWInBurne, H., op. cit, pág. 23.

Bourgoing, Garcia Mt:hCADAL, J., op. cit., págs. 1.027-1.028; los comentarios de Townsend, en ibidem, pág. 1.428; los de Swinburne, en SwineuRnE, H., op. cit, págs. 348-349.

Cossio, J.M. de, op. cit., Tomo I, pág. 681.

Garcia Mehcadal, J., op cit., pág. 1.010 
tadora de los valores nobiliarios y caballerescos y, yendo más allá, del poder en su máxima instancia. Rituales, al tiempo, compatibles con una mentalidad ilustrada, como por ejemplo la de Jovellanos, que reservaba a la nobleza el protagonismo de uregocijos y fiestas [...] que despertarían hasta cierto punto aquella varonil y bizarra galantería de nuestros antiguos caballeros, de que apenas ha quedado débil sombra [...] y las capitales van perdiendo hasta la memoria» ${ }^{72}$.

Jovellanos, desde el utilitarismo y desde una concepción de la fiesta como pedagogía al servicio de los ideales de la llustración, podía suscribir determinados contenidos de la fiesta barroca porque ésta, que con sus demasías sensoriales embelesaba y aturdía prácticamente a toda la sociedad, tenía otra función muy precisa: la de fortalecer el acortesamiento de los nobles y la vinculación de éstos con el monarca a través, como reveló $\mathrm{N}$. Elias, del ceremonial y de la etiqueta ${ }^{73}$. Era ésta una forma más de ejercer el patronazgo real, de que un monarca retirara favores o premiara con pequeños gestos cuando, como escribió el duque de Saint Simon pensando en Luis XIV, "No se le ocultaba que no tenía suficientes gracias que dispensar para impresionar constantemente" ${ }^{74}$. Los balcones de la Plaza Mayor de Madrid, por ejemplo, podian servir muy bien para que los monarcas ejercitaran su patronazgo; comentando una "Fiesta real» de toros, un viajero de finales del siglo XVII había escrito:

«No son [los propietarios] los dueños de sus casas ese día [el de la co rrida], dependiendo del rey el colocar allí a quien le plazca. Todos los empleados de los Consejos y de la Casa Real tienen alli sus puestos gratis. Varios se los dan a sus gentes como recompensa" ${ }^{75}$.

También Bourgoing da testimonio de otra forma más —digamos que igualmente elemental- de desplegar el patronazgo regio, al referirse a los ejercicios ecuestres participados por miembros de la familia real y miembros de la corte en Aranjuez a que hemos aludido: "Para que los cortesanos más adictos encontrasen algún atractivo en este baile de centauros, era preciso, nada menos, que gozasen del honor que significa tomar parte en tales diversiones junto a los hijos del monarca y contribuir a su diversión" ${ }^{76}$.

Jovellanos, G. M. de. op. cit., pág. 125 (de la edición de José Lage, Madrid, Ed. Cátedra,

ElIAS, N., La sociedad cortesana. Madrid, Ed. Fondo de Cultura Económica, 1993, passim. Citado, Ibidem, pág. 163.

Garcia Mercadal, J., op. cit., pág. 75

lbidem, pág. 1.028. 
Finalmente, la mirada a la fiesta privada, que ocupa un reducido espacio en el conjunto de las impresiones recreadas por los viajeros. Una fiesta celebrada exclusivamente en torno a la comensalidad, aunque, por supuesto, no la cotidiana.

Todo lo que al respecto hemos hallado se refiere a los denominados «refrescos», algo más que una simple merienda ofrecida por personas privadas o por instituciones: un mecanismo de sociabilidad. Bourgoing lo expresa nítidamente: "Tienen los españoles, además de los bailes particulares y los conciertos, otros puntos de reunión, como son las tertulias y los refrescos" ${ }^{77}$.

Pero mientras que las tertulias se inscriben en una sociabilidad, digamos, ordinaria, como los paseos, la asistencia al teatro o a la taberna, los refrescos tienen otra dimensión. Al menos los de carácter extraordinario, que, a diferencia de la simple merienda ofrecida a quienes acudían de visita a una casa, constituían una fiesta y que son a los que atienden los viajeros. Leamos lo escrito por, de nuevo, Bourgoing: «En las ocasiones más solemnes, cuando se trata de celebrar un bautizo o el cumpleaños del dueño de la casa, el refresco es un asunto importante y muy dispendioso. Se invita a todos los conocidos» 78 ; o lo escrito por Townsend: "Los grandes señores dan el día de sus bodas refrescos [...]; eso es lo que hizo el hermano del conde de Floridablanca, que tuvo lugar mientras estaba yo en Madrid ' ${ }^{79}$. También, recuérdese, con un refresco, al que asistieron seiscientos invitados notables de la ciudad, obsequiaron los caballeros maestrantes de Valencia al infante don Antonio Pascual.

Los refrescos a los que se refieren nuestros viajeros eran en todos los casos de tipo nobiliario. Una vez reunidos y presentados los invitados, aparecen en escena, sírvanos la descripción de Peyron, "Varias jóvenes sirvientas llevando bandejas cargadas de bizcochos y de agua pura helada; tal es el comienzo del refresco, que se termina con tazas de chocolate, confituras líquidas y dulces» ${ }^{80}$. Un paisaje de golosinas descrito también por otros viajeros que hacen referencia igualmente al refresco.

Éste podía concluir rebasada ya la medianoche, más aún si hacía acto de presencia la música. Al que, según él, asistió Lantier en casa de la duquesa valenciana doña Leonor Silva - ¿de los Silva y Portocarrero?- comenzó por el minué, cuya "gravedad y aburrimiento» fueron disipados

\footnotetext{
Ibidem, pág. 996.

Ibidem.

Ibidem, pág. 1.641

Ibidem, pág. 883.
} 
"Cuando una guitarra, unida a dos violines, hizo oír el riente fandango. Ese aire nacional, como una chispa eléctrica, hirió, animó todos los corazones; casadas, solteras, jóvenes, viejos, todo pareció resucitar, todos repetían ese aire tan poderoso sobre los oídos y el alma de un español [...]. Después del fandango vinieron las seguidillas [...]. Acabó la fiesta a la una de la mañana” ${ }^{81}$.

Aun siendo el refresco la antítesis de las corridas de toros, dado su carácter clasista y su opacidad social -frente al interclasismo y la transparecia social que, como ya apuntamos, Gil Calvo halla en las corridas-, esa presencia de lo popular en casa de la duquesa valenciana nada tiene de disonante. La escena descrita por Lantier, la viviera o no, tómese como alegoría de una realidad española setecentista que no escapó ni a extranjeros ni a nativos: la del arrebato casticista, maridaje de lo galante y lo plebeyo, del achulamiento y del majismo; de, en suma, ciertos componentes de la cultura popular y de la de las elites tradicionales. Por el contrario, el refresco al que asistió Townsend, ya lo mencionamos, concluyó estrictamente con una pequeña ópera compuesta para la ocasión, sin concesiones a lo popular, es decir, a fandangos, seguidillas y boleros.

Tal vez los dramas líricos representaran un habitual fin de refresco en ciertas casas nobiliarias, a tenor de lo que el francés $E$. de Silhuette escribia, hacia 1730, relativo a que el palacio del duque de Osuna contaba con un palacio para la representación de óperas ${ }^{82}$.

Recreándose en ellas, oyendo música, bailando, viendo bailar, hablando o degustando confituras, se establecían o reforzaban lazos de amistad y de intereses, se ampliaba el capital de relaciones sociales. Además, cuando en el refresco había miembros de la familia real, la presencia en él no sólo era un honor, sino también una obligación, pues la inasistencia podía tomarse como un desaire hacia la casa reinante.

Y ya, a modo de recapitulación, digamos que, al igual que en otros campos historiográficos, la literatura de viajes ha revelado una notable riqueza como fuente para el análisis de la fiesta en la España del siglo XVIII.

Incuestionablemente, es la de los toros la que a todos sedujo, aunque también a todos estremeció. Los viajeros describen un festejo en proceso de cambio definido por su profesionalización, tecnificación y codificación. Proceso asociado a un inexorable abandono del ruedo por parte de los

Ibidem. pág. 1.152.

lbidem, pág. 254 
históricos oficiantes de la fiesta - los caballeros-y su sustitución por individuos pertenecientes, dentro de una sociedad estamental, al tercer estado. Proceso que a la vez proyecta el cambio social que se está produciendo en España y del que la burguesía será la principal beneficiaria. Pero también las transformaciones en la fiesta taurina hablan de la emergencia de una llustración popular, ajena a la oficial y constituida desde la base, que se manifiesta de manera más acabada en la figura del torero, ejemplificación de la modernidad del sujeto, responsable y racional, que acabará sometiendo lo natural, instintivo y brutal, representado por el toro.

Además, a los viajeros, al menos a algunos, no les pasó desapercibida la plural dimensión económica de lo taurino, con sus diversas externalidades, entre otras las que iban desde la cría del toro hasta su consumo en las carnicerías, o su virtualidad para estimular la aparición del empresario moderno, atento a hacer del ocio una actividad lucrativa.

Una atención menor, aunque muy estimable desde el punto de vista cualitativo, prestaron los viajeros al ritual propiciado por las festividades de la Iglesia, sobremanera las de Semana Santa y el Corpus. Sus valoraciones apuntan en todos los casos a la condena de una fenomenologia devocional, acorde con el catolicismo barroco popular, poblada de estridencias. Salvo las prohibiciones o el control formal de ciertas prácticas, un proyecto suscrito tanto por el poder político como por la jerarquía eclesiástica, todo parece indicar que el cambio se halla ausente de la fiesta religiosa. Al contrario de lo que sucede con la de los toros, en materia de religiosidad no puede hablarse de la emergencia de una llustración desde la base social; el catolicismo vivido por la mayor parte de la sociedad era extraño a la idea de individuo y de responsabilidad personal, $y$, en consecuencia, a la de sujeto moderno. Lo cual no constituye en absoluto una incoherencia respecto a lo que sucede en la fiesta taurina, pues el proceso modernizador, si planteamos en estos términos el cambio, es inicialmente conjunción de contrarios, confluencia de lo contradictorio.

Mas también en la fiesta pública promovida por los monarcas o por instituciones en honor del rey o de cualquier otro miembro de la familia real las permanencias se hacen patentes. El reducido grupo de viajeros que da cuenta de ella informa de que lo caballeresco y galante, como no podía ser menos, se atrinchera en dicha fiesta. Sin embargo, lo caballeresco es plenamente conjugable con la llustración oficial, es decir, con la formulada desde la cúspide social, que valora positivamente ese espítiru cuando, en el marco político del Absolutimo ilustrado, se pone al servicio, no de la autoexaltación de una nobleza reticente con el monarca, sino de una nobleza que acepta como incontestable la soberania del mismo. 
$Y$ en un nivel de atención aún menor en el conjunto de la literatura de viajes aparece la fiesta privada, circunscrita en exclusividad a la que se desarrolla en ambientes nobiliarios, aunque en ella pueda tener cabida, a través de la música o del baile, lo popular. Una fiesta articulada en torno al refresco, un ejercicio de sociabilidad horizontal y hasta para la adulación cuando se celebra con el fin de agasajar al rey o a miembros de su familia.

Por último, no es apreciable en los viajeros una tendencia al estereotipo estridente y radicalmente desviado de la realidad que las investigaciones históricas nos muestran. El español del setecientos no es un caso atípico de relativa ociosidad en la Europa de la época, pues el calendario laboral es todavía en ella muy dependiente del agrícola. La violencia que rodea una corrida de toros no se halla muy distante de la que puede encontrarse, por ejemplo, en la Inglaterra del mismo tiempo, en donde se participa como espectador y se apuesta en peleas de gallos o en luchas entre perros y toros. En cuanto a las desmesuras y filopaganismos de ciertas manifestaciones de religiosidad, que tanto reprobaban los viajeros, pueden hallarse también en otras naciones de la Europa católica.

La valoración, en fin, a que da lugar la percepción de la fiesta en la España setecentista por parte de los extranjeros que a ella acuden pudiera ser suscrita sin reservas por algunos españoles coetáneos suyos, del mismo modo que, según lo que nos han aportado otras fuentes y el estudio de otros problemas, los historiadores de hoy tendríamos que admitir lo certero o lo ponderado de su mirada. 